DOI: https://doi.org/10.47405/mjssh.v6i2.631

\begin{tabular}{|c|c|}
\hline 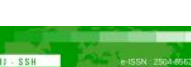 & Malaysian Journal of Social Sciences and Humanities (MJSSH) \\
\hline Malaysian Journal of & Volume 6, Issue 2, February 2021 \\
\hline (MJ-ssH) & e-ISSN : 2504-8562 \\
\hline & $\begin{array}{l}\text { Journal home page: } \\
\text { www.msocialsciences.com }\end{array}$ \\
\hline
\end{tabular}

\title{
Pengaruh Latihan Bercirikan Ketenteraan Keatas Pembangunan Prestasi Pekerja: Organisasi Sektor Awam di Malaysia
}

\author{
Mohd Safix Lamsah¹, Rosniza Aznie Che Roseㄹ, Mohammad Daud Johari², Rogis Baker², Mohd Sani \\ Ismail ${ }^{3}$ \\ ${ }^{1}$ Fakulti Sains Sosial dan Kemanusiaan, Universiti Kebangsaan Malaysia (UKM) \\ ${ }^{2}$ Fakulti Pengajian dan Pengurusan Pertahanan, Universiti Pertahanan Nasional Malaysia (UPNM) \\ ${ }^{3}$ Fakulti Pengajian Kontemporari Islam, Universiti Sultan Zainal Abidin (UNISZA) \\ Correspondence: Mohd Safix Lamsah (abumushtarique@gmail.com)
}

\begin{abstract}
Abstrak
Latihan di tempat kerja merupakan faktor kritikal dalam meningkatkan kekuatan sumber manusia khususnya pembentukan prestasi pekerja. Pengurusan sumber manusia yang optimis akan memastikan latihan tersebut memberi impak yang positif. Namun begitu, kebanyakan latihan yang dilaksanakan di kebanyakan organisasi sektor awam masih di tahap yang memuaskan. Justeru, kajian ini dijalankan bagi mengkaji pengaruh latihan bercirikan modul ketenteraan keatas pembangunan modal insan di Kementerian Pertahanan, Malaysia. Kaedah pengumpulan data daripada borang soal selidik yang diedarkan kepada 92 responden menggunakan formula Taro Yamanae. Prestasi pekerja berasaskan modul ketenteraan dianalisis berdasarkan analisis kebolehpercayaan, ujian kenormalan, analisis deskriptif, analisis kolerasi dan analisis regresi linear menggunakan Statistical Package for Social Sciences. Daripada ujian kenormalan, data Skewness dan Kurtosis bertabur secara normal yang menunjukkan nilai kepencongan berada dalam lingkungan 2.0 titik cut-off. Analisis deskriptif menunjukkan taburan kekerapan tahap prestasi pekerja pada tahap tertinggi bersamaan 90.32 peratus. Melalui analisis kolerasi, penggunaan modul ketenteraan mempunyai kolerasi yang tinggi. Analisis regresi linear turut menunjukkan terdapat hubungan yang signifikan antara modul ketenteraan terhadap prestasi pekerja khususnya dari aspek kerjasama sepasukan. Justeru, latihan berasaskan modul ketenteraan berupaya melatih mental dan fizikal pekerja awam khususnya mengurangkan tekanan bekerja dalam organisasi. Malah, perkembangan kognitif dan psikomotor pekerja amat bersesuaian dengan skop kerja dengan latihan tersebut. Pelaksanaan latihan bercirikan ketenteraan secara holistik telah memberi impak yang positif dalam pencapaian matlamat, misi dan visi organisasi sekali gus mengoptimumkan sumbangan modal insan memacu wawasan negara yang berjaya.
\end{abstract}

Kata kunci: mobiliti, modul ketenteraan, pengurusan latihan, prestasi pekerja, sumber manusia

\section{The Influence of Military Oriented Training on Employee Performance Development: Public Sector Organisation in Malaysia}

\begin{abstract}
Training in the workplace is a critical factor in improving the strength of human resources, especially the formation of employee performance. Optimistic human resource management will ensure that the training has a positive impact. Nevertheless, most of the training implemented in most public sector organizations is still at a satisfactory level. Thus, this study examines the influence of training oriented
\end{abstract}


by military modules on the development of human capital for civil servants in the Ministry of Defense, Malaysia. The data collection method from the questionnaire was distributed to 92 respondents using Taro Yamanae formula. Military module-based employee performance was analyzed based on reliability analysis, normality test, descriptive analysis, correlation analysis and linear regression analysis using Statistical Package for Social Sciences. From the normality test, Skewness and Kurtosis data are normally distributed which shows the deviation value is within 2.0 cut-off. Descriptive analysis shows the frequency distribution of employee performance level at the highest level equivalent to 90.32 percent. Through correlation analysis, the use of military modules has high correlation. Linear regression analysis shows that there is a significant relationship between military modules on employee performance, especially aspects of teamwork. Thus, military module-based training is able to mentally and physically train civil servants in reducing work stress in the organization. In fact, employee cognitive development is very much in line with the scope of work and training. The implementation of holistic military training has a positive impact on the achievement of goals, missions and visions further optimizing the contribution of the workforce in the organization.

Keywords: human resource, military modul, ministry mobility, training management, work performance

\section{Pengenalan}

Mendepani era mobilisasi, sektor pekerjaan telah menyaksikan pelbagai perubahan yang drastik dalam pembaharuan pengurusan organisasi. Kebanyakan organisasi amat memerlukan sumber manusia yang sentiasa berdaya saing dan dalam masa yang sama, organisasi perlu memfokuskan usaha yang perlu dilakukan terhadap pembangunan modal insan. Perkara ini termasuk dengan menjalankan penstrukturan semula secara menyeluruh dalam mutu latihan yang dijalankan di tempat kerja. Namun begitu, latihan yang dijalankan di kebanyakan organisasi masih kurang memberi impak terhadap pembangunan modal insan. Hal ini dikaitkan dengan modul yang dilaksanakan tidak berkesan terhadap peningkatan prestasi pekerja. Impaknya, setiap organisasi terpaksa berhadapan dengan pelbagai persaingan disebabkan oleh globalisasi, perubahan dalam teknologi, politik dan persekitaran ekonomi (Hald et al., 2018). Maka, kebanyakan organisasi memerlukan langkah yang proaktif dalam menjalankan latihan yang bersesuaian ke arah pembentukan prestasi pekerja yang benar-benar mencapai standard. Tanggungjawab dalam memperkasakan ilmu, kepakaran dan kemahiran pekerja adalah matlamat utama yang perlu diberi penekanan. Justeru, latihan yang bertepatan dengan misi, visi dan objektif di tempat kerja perlu dijadikan indikator penting dan menyusun langkah drastik yang perlu diamalkan oleh organisasi bagi mencapai impak yang ditetapkan. Pihak pengurusan juga perlu cakna terhadap pelan pembangunan latihan yang lebih bersesuaian dengan keperluan pekerja agar mencapai setiap perspektif dalam organisasi.

Dalam arus pemodenan, Kementerian Pertahanan, Malaysia bukan sahaja memerlukan peralatan ketenteraan yang terkini semata-mata, malah faktor kejayaan organisasi juga dilihat dan diberi perhatian penuh dari sudut kekuatan sumber manusia. Kementerian ini tidak terhad dalam kalangan pegawai dan anggota tentera dalam kepimpinan organisasi, malah pekerja awam juga memainkan peranan yang amat penting dalam membentuk organisasi yang fleksibel. Justeru, bahagian pengurusan sumber manusia perlu memainkan peranan yang penting dalam mengoptimumkan prestasi pekerja agar berupaya mengekalkan matlamat organisasi yang lebih eksklusif (Russell et al., 2018). Elemen kerjasama sepasukan antara pekerja awam dan tentera di Kementerian Pertahanan, Malaysia memerlukan tindak balas yang baik seperti kecekapan masa yang tinggi, mental dan fizikal yang ampuh serta berupaya untuk melaksanakan tugasan di bawah tekanan bekerja. Oleh hal demikian, bahagian pengurusan sumber manusia yang peka terhadap pembangunan pekerja akan sentiasa mencari alternatif untuk meningkatkan mutu pekerja yang mampu mencapai misi, visi dan objektif organisasi (Hoch, 2017). Namun begitu, isu ini tidak mendapat perhatian dalam kajian yang lepas, malah tiada bukti substantif yang dikaitkan terhadap latihan dengan prestasi pekerja sektor awam di Malaysia. Oleh itu, terdapat jurang dalam bidang ilmu kerana tiada kajian yang mengkaji pengaruh modul ketenteraan terhadap prestasi pekerja awam dan artikel ini akan menangani jurang dalam isu tersebut. 
Justeru, tujuan artikel ini adalah untuk mengkaji pengaruh modul ketenteraan dalam latihan terhadap prestasi pekerja awam di Kementerian Pertahanan, Malaysia. Objektif utama artikel ini adalah untuk mengenal pasti tahap keberkesanan latihan bercirikan ketenteraan terhadap prestasi pekerja awam khususnya dalam aspek kerjasama sepasukan. Kedua, mengkaji hubungan antara latihan bercirikan ketenteraan terhadap prestasi pekerja awam. Selain itu, terdapat beberapa persoalan dalam kajian iaitu apakah tahap keberkesanan latihan terhadap prestasi pekerja dan adakah terdapat hubungan yang positif antara latihan dengan prestasi pekerja.

\section{Sorotan Literatur}

Latihan di tempat kerja bercirikan ketenteraan merupakan modul yang sering digunakan di kebanyakan organisasi di luar negara kerana banyak menghasilkan impak yang positif kepada tahap prestasi pekerja. Terdapat banyak modul yang digunakan dalam latihan, namun modul ketenteraan dipilih dan digunakan oleh negara-negara Barat kerana mempunyai elemen bagi membentuk seseorang untuk patuh kepada arahan yang berlandaskan disiplin dan kepimpinan, menguji mental dan fizikal, membentuk kerjasama sepasukan dan semangat setia kawan, menghormati dan patuh kepada masa serta bekerja secara muafakat (Luria et al., 2019). Keseronokan dalam latihan bercirikan ketenteraan menjadikan peserta akan mengingati peristiwa tersebut. Hal ini kerana, latihan yang lasak memberi kesan keseronokan dan peningkatan kognitif peserta (O'Neill, 2018). Tambahan pula, elemen ketenteraan yang diterapkan adalah berfokus untuk membentuk tahap prestasi kerja yang tinggi dan menghapuskan jurang bekerja. Menurut Helton et al. (2019), ciri-ciri latihan yang berasaskan ketenteraan ialah pembelajaran kendiri (self instructional), menyeluruh (self contained), berdikari (stand alone), penyesuaian (adaptive), mesra pengguna (user friendly) dan berterusan (consistant).

Mackay et al. (2017) dalam kajiannya terhadap pekerja-pekerja baharu dalam proses sosialisasi di organisasi mendapati bahawa, terdapat hubungan yang signifikan terhadap modul latihan yang digunakan terhadap proses sosialisasi pekerja. Hal ini kerana, modul latihan yang bersesuaian dengan objektif latihan akan menggalakkan kefahaman peserta untuk mendalami isi kandungan latihan dengan baik. Mackay et al. (2017) juga menyimpulkan, pekerja yang berterusan menyertai latihan dapat memberi sumbangan kepada kepuasan bekerja, keupayaan untuk bersaing, tanggungjawab kepada bidang tugas dan mengurangkan kemerosotan prestasi. Kajian ini turut disokong oleh kajian yang dijalankan oleh Pagnini et al. (2019), mengenai pemilihan modul latihan dan pembangunan personaliti di sektor pengurusan. Hasil kajian mendapati, kejayaan sesuatu program latihan amat bergantung kepada pemahaman antara peserta dan penceramah terhadap objektif-objektif latihan. Penggunaan modul latihan yang tidak sesuai dengan bidang tugas peserta, tidak akan memberi apa-apa perubahan dan peningkatan ilmu pekerja dalam organisasi. Malah, Pagnini et al. (2019) turut merumuskan, penilaian yang konsisten terhadap kualiti tugasan, kemahiran dan tingkah laku selepas latihan adalah sebahagian daripada cara untuk mempertingkatkan kesan positif dalam latihan. Justeru, peningkatan atau penurunan prestasi pekerja amat bergantung kepada keupayaan melaksanakan tugasan sama ada respond yang positif atau negatif. Untuk meningkatkan prestasi pekerja, perubahan harus dilakukan terhadap penerimaan individu, pelaksanaan latihan di tempat kerja dan motivasi (He et al., 2019).

Seterusnya, dalam kajian yang telah dilakukan oleh Yuen et al. (2018), modul dalam latihan adalah domain utama pengisian untuk diselaraskan dengan tugas pekerja dalam organisasi. Modul latihan perlulah bertepatan dengan ciri-ciri pekerja dan keperluan bidang tugas semasa agar ilmu selepas latihan (output) dapat aplikasikan untuk melaksanakan kerja dengan lancar. Sebaliknya, jika latihan tersebut yang tidak berkaitan atau tidak praktikal, maka akan memberi kesan negatif kerana pekerja tidak mampu untuk menyumbangkan 'output' kepada organisasi. Kajian ini selaras dengan dapatan kajian yang dilakukan oleh Saliba de Oliveira et al. (2018), di mana modul dalam latihan merupakan faktor tarikan dalam penglibatan peserta untuk menyertai latihan. Hal ini kerana, aspek kandungan latihan, objektif, lokasi dan kemudahan latihan yang digunakan terbukti penting dalam mengelakkan peserta menjadi hilang fokus dan tidak berminat menjalani latihan. Pekerja yang mempunyai semangat terhadap pelaksanaan tugas akan memandang serius aspek latihan yang disertai yang seterusnya memberi lonjakan terhadap komitmen kerja dan penambahbaikan pengetahuan kendiri. Tambahan pula, pekerja turut diberikan rangsangan dan penetapan matlamat terhadap bidang tugas kerana tetapan 
minda (mind-set) pekerja akan disetkan kepada mencapai matlamat dengan bersungguh-sungguh demi menjamin prestasi kerja yang terbaik (Ronen et al., 2017).

Namun begitu, kebanyakan latihan yang dijalankan di kebanyakan organisasi sektor awam masih berada pada tahap yang memuaskan. Terdapat pelbagai faktor yang menyumbang kepada kekurangan impak dalam latihan di sesebuah organisasi. Antara faktor tersebut ialah pengurusan latihan yang tidak efektif. Menurut kajian yang telah dilakukan oleh Hoch et al. (2017), dapatan kajian membuktikan latihan yang tidak memberi impak akan berlaku apabila pengurusan yang tidak optimis dan tidak peka terhadap pembangunan modal insan tetapi hanya fokus kepada matlamat pencapaian organisasi sematamata. Kedua, kekurangan pengetahuan dan pengalaman dalam kalangan instruktor. Faktor ini disokong oleh kajian yang telah dilakukan oleh oleh Piirainen (2019), di mana pengetahuan dan pengalaman yang diperoleh oleh instruktor yang terhad akan mengurangkan skop latihan yang disertai oleh pekerja. Hal ini kerana, untuk membimbing pekerja ke arah peningkatan ilmu dan kemahiran, instruktor perlulah mempunyai kemahiran dan kepakaran yang luas agar setiap maklumat yang disampaikan dapat memberi pendedahan kepada peserta latihan. Ketiga, objektif latihan yang tidak jelas. Objektif latihan adalah sandaran yang penting kerana pekerja akan berusaha secara mental dan fizikal untuk mendapatkan maklumat yang disampaikan. Kebanyakan organisasi cuma menghantar pekerja untuk menjalani latihan tanpa mengenal pasti objektif latihan dan hasil yang boleh diimplementasikan kepada organisasi.

Faktor yang seterusnya ialah kaedah latihan yang tidak bersesuaian dengan latar belakang, umur, jantina, skop kerja dan perjawatan pekerja. Penyataan ini disokong oleh kajian yang dilakukan oleh Ivarsson (2019), terdapat pelbagai teknik latihan yang boleh digunakan tetapi tidak semua teknik dan pendekatan tersebut bertepatan dengan latihan yang dijalankan. Malah, beliau berpendapat bahawa, masalah terbesar dalam pemilihan kaedah latihan terletak kepada kegagalan pihak pengurusan latihan untuk menyedari perbezaan antara teori pembelajaran dan prinsip-prinsipnya serta sejauh mana kaedah tersebut boleh digunakan. Faktor yang terakhir ialah kekurangan motivasi untuk menyertai latihan dalam kalangan pekerja. Menurut kajian yang dilakukan oleh Han et al. (2019), individu yang mempunyai kekurangan motivasi akan mengalami kesanggupan yang lemah untuk menghadiri latihan dan memberi kesan negatif kepada hasil pembelajaran tersebut. Oleh itu, sebelum sesuatu latihan dijalankan di tempat kerja, segala aspek pengurusan latihan perlu diuruskan dengan baik agar pekerja mempunyai impak yang positif terhadap pembangunan modal insan.

Dilihat dari perspektif berbeza, prestasi pekerja mempunyai elemen yang luas untuk dinilai. Menurut kajian yang telah dijalankan oleh Pfister et al. (2017), elemen kerjasama sepasukan adalah elemen yang menjadi jurang bekerja dalam kebanyakan organisasi kerana pekerja yang ramai memerlukan nilai saling membantu, toleransi, saling memberi sokongan dan sebagainya. Penyataan ini disokong berdasarkan kajian yang dilakukan oleh Saliba et al. (2018), iaitu kebanyakan organisasi di luar negara mempunyai masalah kekurangan kerjasama sepasukan antara pekerja. Impak daripada kekurangan kerjasama sepasukan ini, pekerja lebih gemar untuk melaksanakan tugasan seorang diri, mempunyai sikap mementingkan diri sendiri dan tidak mempedulikan masalah tugas yang dihadapi oleh rakan sekerja yang lain. Kerjasama sepasukan merujuk kepada sekumpulan pekerja dalam organisasi yang melaksanakan tugas secara berganding bahu antara satu sama lain dan bergabung bagi mencapai matlamat kumpulan (Hoch 2017). Di samping itu, menurut Padlee (2019), kerjasama sepasukan merujuk kepada sekumpulan dua atau lebih manusia yang berinteraksi dan menyelaras tugasan atau kerja mereka bagi mencapai matlamat umum yang disasarkan bersama. Manakala Ma et al. (2019), menyatakan bahawa kerjasama sepasukan sebagai satu pemahaman dan komitmen di antara ahli pasukan ke arah pencapaian maklumat pasukan dan mengurangkan perselisihan faham yang wujud dalam ahli pasukan kerja. Dalam konteks kajian, kerjasama sepasukan merujuk kepada kerjasama antara pekerja awam dan tentera di Kementerian Pertahanan, Malaysia terhadap jurang pekerjaan dalam melaksanakan tugasan dalam organisasi yang sama. Oleh itu, kerjasama sepasukan merupakan satu unit dalam organisasi dan saling berinteraksi untuk menyebarkan maklumat dan keputusan bagi membantu ahli-ahli pasukan menjalankan tugas dalam ruang sempadan tanggungjawab yang telah ditetapkan. 


\section{Metod Kajian}

Kajian ini merupakan suatu kajian tinjauan berkaitan tahap prestasi pekerja awam setelah menyertai latihan bercirikan modul ketenteraan. Kajian yang dijalankan adalah berbentuk deskriptif yang menggunakan pendekatan kuantitatif dengan melibatkan proses tinjauan melalui kaedah pengumpulan data. Borang soal selidik yang digunakan dalam kajian ini mempunyai tiga bahagian utama. Bahagian pertama merupakan profil peserta latihan, bahagian kedua ialah konstruk untuk mengukur item modul ketenteraan manakala bahagian ketiga ialah konstruk untuk mengukur tahap prestasi pekerja awam selepas menghadiri latihan. Data kajian dianalisis menggunakan analisis kebolehpercayaan, ujian kenormalan, analisis deskriptif, analisis kolerasi dan analisis regresi linear.

Berdasarkan objektif-objektif kajian, pengkaji juga menggunakan kaedah temu bual pegawai di Cawangan Latihan, Bahagian Pengurusan Sumber Manusia Kementerian Pertahanan, Malaysia bagi menentukan ketepatan maklumat, kesahan analisis dan melihat kefahaman tentang modul ketenteraan terhadap prestasi pekerja awam. Terdapat 92 data responden yang telah diperoleh dan dianalisis berdasarkan formula Taro (1967). Instrumen yang digunakan dalam kajian ini adalah borang soal selidik berstruktur yang disesuaikan untuk menilai prestasi pekerja daripada beberapa aspek yang dikenal pasti pengkaji.

Populasi terdiri daripada pekerja awam di Kementerian Pertahanan, Malaysia yang mengikuti beberapa kursus yang menggunakan modul ketenteraan. Kaedah persampelan yang digunakan dalam kajian ini ialah persampelan rawak mudah. Terdapat tiga latihan yang menggunakan modul ketenteraan. Bagi pecahan kursus dan jumlah peserta yang hadir, Kursus Pengurusan Perkhidmatan dan Pentadbiran dihadiri oleh 37 orang peserta. Bagi Kursus 'Human Resource Leadership Development' dihadiri oleh 43 orang peserta dan Kursus Asas Kepimpinan dan Pembangunan Profesionalisme dihadiri oleh 40 orang peserta. Maka, jumlah keseluruhan peserta yang mengikuti latihan bercirikan modul ketenteraan ialah 120 peserta. Saiz sampel kajian yang digunakan dalam kajian ini adalah dengan nisbah 0.5 yang mewakili aras keyakinan (e) iaitu sebanyak 92 orang pekerja awam yang mengikuti latihan bercirikan modul ketenteraan.

\section{Kebolehpercayaan}

Pengumpulan data bagi kajian ini dianalisis berdasarkan respons daripada soal selidik bagi setiap konstruk. Maka, adalah penting untuk menjalankan ujian kebolehpercayaan Cronbach alpha. Kesemua konstruk dalam latihan iaitu modul ketenteraan, instruktor dan prestasi pekerja diukur bagi mendapatkan analisis yang bebas daripada kesilapan semasa responden menandakan borang soal selidik. Daripada analisis ini menunjukkan, ukuran Cronbach alpha bagi kesemua konstruk utama melebihi titik penentu 0.70 di mana pekali Cronbach alpha bagi domain dalam latihan ialah 0.824 , pekali Cronbach alpha bagi instruktor ialah 0.871 dan pekali Cronbach alpha bagi konstruk prestasi pekerja adalah 0.848. Jadual 1 di bawah menunjukkan hasil kajian bagi analisis Cronbach alpha.

Jadual 1: Nilai Cronbach alpha mengikut konstruk

\begin{tabular}{lll}
\hline Konstruk & Bil. Item & Nilai Cronbach Alpha \\
\hline Modul ketenteraan & 10 & 0.824 \\
Instruktor & 10 & 0.871 \\
Prestasi pekerja & 10 & 0.848 \\
\hline
\end{tabular}

\section{Ujian kenormalan}

Terdapat tiga cara yang digunakan untuk menguji tahap normaliti data iaitu Skewness, Kurtosis dan Probability Plot. Menurut George dan Mallery (2003), bagi Skewness dan Kurtosis, mereka mereka mencadangkan bahawa nilai kepencongan adalah dalam lingkungan \pm 2.0 titik cut-off. Penemuan dalam kajian ini amat signifikan dengan cadangan tersebut apabila domain dalam latihan iaitu modul ketenteraan menunjukkan nilai Skewness -0.697 dan nilai Kurtosis 0.821. Domain instruktor pula menunjukkan nilai Skewness -761 dan nilai Kurtosis 0.475. Prestasi pekerja pula menunjukkan nilai 
Skewness -0.795 dan nilai Kurtosis 0.868. Melalui ujian kenormalan, penemuan kajian terhadap ketigatiga item adalah normal. Nilai kepencongan bagi setiap item berada dalam skala $( \pm 2)$. Malah, nilai kurtosis bagi setiap item turut berada dalam skala $( \pm 2)$.

Jadual 2: Nilai kepencongan mengikut konstruk

\begin{tabular}{llll}
\hline Konstruk & $\begin{array}{l}\text { Kepencongan } \\
\mathbf{( \pm 2 )}\end{array}$ & $\begin{array}{l}\text { Kurtosis } \\
\mathbf{( \pm 2 )}\end{array}$ & Univariate Normality Assumption \\
\hline Modul ketenteraan & -0.697 & 0.821 & Normal \\
Penyampaian penceramah & -0.761 & 0.475 & Normal \\
Prestasi pekerja & -0.795 & 0.868 & Normal \\
\hline
\end{tabular}

\section{Hasil Kajian}

\section{Analisis deskriptif tahap keberkesanan modul ketenteraan terhadap prestasi pekerja awam}

Analisis ini dibentuk untuk mengkaji modul ketenteraan yang digunakan kepada pekerja awam terhadap kerjasama sepasukan dalam organisasi. Analisis deskriptif digunakan bagi menunjukkan jumlah purata min bagi setiap item mengikut tahap yang telah ditetapkan. Tahap yang digunakan adalah tahap rendah, sederhana dan tinggi. Berdasarkan kepada Jadual 3, skor minimum bagi item prestasi kerja adalah 2.70 dan maksimum pula adalah 5.00. Ini memberikan julat bagi item menjadi 2.30. Nilai median pula menunjukkan nilai 4.30 dengan sisihan piawai sebanyak 0.46 . Selain itu, nilai min untuk tahap prestasi kerja adalah 4.26 yang menunjukkan kerjasama sepasukan dalam kalangan pekerja adalah pada tahap yang tinggi.

Berdasarkan analisis ini, hasil kajian menunjukkan nilai percentile ke-25 bagi prestasi pekerja ialah 3.95, nilai percentile ke-75 ialah 4.60 dan Interquartile Range (IQR) ialah 0.65 . Nilai-nilai yang diperoleh dari percentile ke-25 sehingga percentile ke-75 memberi bukti bahawa 50\% daripada responden yang terdiri daripada pekerja awam mempunyai tahap kerjasama sepasukan antara 3.95 hingga 4.60. Nilai percentile ke-90 untuk item ini ialah 4.80 yang menunjukkan bahawa $90 \%$ daripada responden mempunyai tahap kerjasama sepasukan sebanyak 4.80 atau kurang. Dalam masa yang sama, nilai-nilai ini bermaksud bahawa 10\% daripada responden mempunyai tahap kerjasama sepasukan atas daripada nilai 4.80. Mengikut skor min yang ditetapkan, 1 hingga 2.33 adalah rendah, 2.34 hingga 3.67 adalah sederhana dan 3.68 hingga 5 adalah tinggi merupakan petunjuk tahap bagi setiap item dalam kajian ini. Jadual 3 menunjukkan hasil taburan kekerapan di mana tahap bagi kerjasama sepasukan pekerja awam di Kementerian Pertahanan, Malaysia adalah tinggi (90.32\%) dan sederhana (9.68\%). Tiada responden yang mempunyai tahap prestasi kerja yang rendah selepas mengikuti latihan berasaskan modul ketenteraan. Dapatan kajian ini selari dengan dapatan min yang diperoleh di mana menunjukkan tahap prestasi kerja adalah tinggi.

Jadual 3: Nilai deskriptif prestasi pekerja

\begin{tabular}{ll}
\hline Analisis deskriptif & Prestasi pekerja \\
\hline Min & 4.26 \\
Median & 4.30 \\
Sisihan piawai & 0.46 \\
Minimum & 2.70 \\
Maksimum & 5.00 \\
Julat & 2.30 \\
Interquartile Range (IQR) & 0.65 \\
Percentile & \\
25th & 3.9500 \\
50th & 4.3000 \\
75th & 4.6000
\end{tabular}




\begin{tabular}{ll} 
90th & 4.8000 \\
\hline Tahap & Nilai \\
\hline $\begin{array}{l}\text { Rendah } \\
(1.00-2.33)\end{array}$ & $0(0.0)$ \\
$\begin{array}{l}\text { Sederhana } \\
(2.34-3.66)\end{array}$ & $9(9.7)$ \\
Tinggi & \\
$(3.67-5.00)$ & $84(90.3)$ \\
\hline
\end{tabular}

Modul ketenteraan adalah elemen yang digunakan dalam latihan bagi membentuk prestasi pekerja yang setaraf dengan kehendak pasaran kerja, seiring dengan persaingan globalisasi (Iqbal, 2018). Modul ketenteraan menitikberatkan pengurusan masa yang cekap, kebolehan melaksanakan tugas di bawah tekanan tanpa stres, kecekapan berorganisasi melibatkan kerjasama rakan sekerja, patuh kepada arahan dan gerak kerja organisasi yang produktif. Penyesuaian modul ketenteraan dalam latihan di tempat kerja telah memberi kesan yang positif dalam suasa pekerjaan di Kementerian Pertahanan, Malaysia untuk membentuk prestasi pekerja yang berdaya saing. Hasil kajian menunjukkan, daripada 92 orang responden yang telah menyertai latihan ini, tiada seorang pekerja yang berada di tahap rendah (0\%). Ini membuktikan, selepas pekerja menyertai latihan, pekerja mempunyai peningkatan kendiri yang signifikan dalam melaksanakan tugasan dan latihan bercirikan ketenteraan ini amat bersesuaian dengan pekerja awam kerana elemen ketenteraan yang menerapkan pelbagai ciri untuk membentuk pekerja yang terbaik. Impaknya, seramai 84 peserta bersamaan (90.3\%) berada di tahap yang tinggi manakala selebihnya iaitu 9 peserta bersamaan $(9.7 \%)$ berada di tahap sederhana. Bilangan pekerja yang berada di tahap tinggi ini bukan sahaja berdasarkan penilaian responden selepas menghadiri latihan, malah turut disokong oleh ketua jabatan masing-masing.

\section{Ujian Kolerasi Pearson}

Analisis korelasi dilaksanakan untuk mengkaji perkaitan di antara latihan bercirikan ketenteraan dengan prestasi pekerja awam. Jadual 4 menunjukkan korelasi di antara latihan bercirikan ketenteraan serta analisis kolineariti pelbagai. Hasil kajian ini membuktikan bahawa, item dalam latihan mempunyai korelasi yang signifikan antara item yang lain. Hasil analisis ini mencadangkan bahawa, pemilihan modul dalam latihan di tempat kerja amat penting dan memberi pengaruh kepada prestasi pekerja serta perlu dilaksanakan secara holistik. Analisis korelasi $(r)$ akan menyatakan arah, kekuatan dan kepentingan hubungan di antara kesemua pemboleh ubah yang diukur. Jadual 4 menunjukkan korelasi antara latihan menggunakan modul ketenteraan ke atas prestasi pekerja khususnya dalam aspek kerjasama sepasukan.

Jadual 4: Analisis kolerasi antara item

\begin{tabular}{|c|c|c|c|c|}
\hline \multicolumn{5}{|l|}{ Kolerasi } \\
\hline & & $\begin{array}{l}\text { Prestasi } \\
\text { pekerja }\end{array}$ & $\begin{array}{l}\text { Modul } \\
\text { ketenteraan }\end{array}$ & $\begin{array}{l}\text { Kerjasama } \\
\text { sepasukan }\end{array}$ \\
\hline Prestasi & Kolerasi Pearson & 1 & $.770^{* *}$ & $703 * *$ \\
\hline pekerja & Sig. (2-tailed) & & .000 & .000 \\
\hline Modul & Kolerasi Pearson & $.770 * *$ & 1 & \\
\hline ketenteraan & Sig. (2-tailed) & .000 & & \\
\hline Kerjasama & Kolerasi Pearson & $.703 * *$ & & 1 \\
\hline sepasukan & Sig. (2-tailed) & .000 & & \\
\hline
\end{tabular}

Berdasarkan jadual 4, hasil pekali korelasi bagi item modul ketenteraan dan prestasi pekerja merupakan yang paling tinggi dan signifikan iaitu $(\mathrm{r}=0.770)$. Nilai pekali korelasi $(\mathrm{r}=0.770)$ menunjukkan, hubungan linear yang wujud antara kedua-dua item tersebut merupakan satu hubungan yang positif. Berdasarkan Guildford's rule of thumb, nilai-r $=0.770$ bermaksud terdapat hubungan linear positif 
DOI: https://doi.org/10.47405/mjssh.v6i2.631

yang tinggi di antara kedua-dua item. Hasil tersebut juga menjelaskan bahawa terdapat satu hubungan yang signifikan antara modul ketenteraan dan prestasi pekerja. Oleh itu, penemuan ini dengan jelas menyokong objektif kajian seperti dalam jadual 5.

Jadual 5: Analisis hubungan konstruk

\begin{tabular}{|c|c|c|c|}
\hline \multicolumn{4}{|c|}{ Prestasi pekerja } \\
\hline Item & Pekali & Kekuatan & Kesimpulan \\
\hline Modul ketenteraan & 0.770 & Tinggi & $\begin{array}{l}\text { Terdapat hubungan positif } \\
\text { yang signifikan }\end{array}$ \\
\hline $\begin{array}{l}\text { Kerjasama } \\
\text { sepasukan }\end{array}$ & 0.703 & Tinggi & $\begin{array}{l}\text { Terdapat hubungan positif } \\
\text { yang signifikan }\end{array}$ \\
\hline
\end{tabular}

Modul dalam latihan bercirikan ketenteraan diadaptasi secara tersendiri untuk mencapai sesuatu kemahiran dan pengetahuan berdasarkan matlamat utama organisasi. Di akhir latihan ini, pekerja awam yang bertugas dalam organisasi akan mempunyai nilai dan prinsip-prinsip asas ketenteraan. Pendekatan modul ini dilaksanakan bukan berdasarkan latihan untuk melatih pekerja awam untuk menjadi tentera. Tetapi, menjadikan pekerja awam yang berkhidmat dalam Kementerian Pertahanan, Malaysia berupaya menyesuaikan diri dengan organisasi yang melibatkan pegawai dan anggota tentera serta mempunyai nilai dan personaliti ketenteraan ketika melaksanakan tugas dengan prestasi yang terbaik. Hasil kajian ini menunjukkan bahawa terdapat perkaitan antara modul ketenteraan bersamaan pekali 0.770 dengan kerjasama sepasukan bersamaan pekali 0.703 iaitu kekuatan yang tinggi.

\section{Analisis Regresi Linear: Menentukan Hubungan antara Modul Ketenteraan Terhadap Kerjasama Sepasukan dalam kalangan Pekerja Awam}

Dalam kajian ini, analisis regresi linear digunakan untuk menentukan hubungan antara modul ketenteraan terhadap prestasi pekerja khususnya kerjasama sepasukan dalam kalangan pekerja awam. Satu model dibentuk untuk mewakili kajian dalam meneliti penentuan kritikal item seperti berikut:

\section{Menguji model regresi keseluruhan}

Model regresi:

$$
Y=Y_{0}+\beta_{1} X_{1}+\beta_{2} X_{2}+\beta_{3} X_{3}+\beta_{4} X_{4}+\beta+e
$$

Kesignifikan umum bagi model regresi berganda diuji menggunakan hipotesis berikut:

$$
\begin{aligned}
& H_{0}: \beta_{1}=\beta_{2}=\beta_{3}=\beta_{4} \ldots . \beta_{l} \\
& H_{a}: \text { Sekurang-kurangnya satu pekali regresi } \neq 0 .
\end{aligned}
$$

Penolakan hipotesis nol bermaksud, terdapat satu item peramal yang mampu menambah nilai ramalan yang signifikan bagi item yang lain. Satu analisis regresi berganda telah dijalankan iaitu terdapat dua item dalam latihan dan min prestasi pekerja adalah aspek yang ingin diukur. Model dalam jadual 6 dibawah menunjukkan, terdapat hubungan antara item dalam latihan dan kerjasama sepasukan yang mempunyai nilai kesesuaian yang baik dengan nilai $\mathrm{R}(0.732)$ dan $R^{2}(0.487)$ yang agak yang tinggi. Malah, nilai $\mathrm{R}$ menunjukkan hubungan yang kuat kedua-dua item tersebut. Nilai $R^{2}$ adalah 0.487 dengan ralat piawai 0.856 serta nilai $\mathrm{F}$ yang signifikan iaitu 28.27. Model itu mencadangkan bahawa item latihan menerangkan sejumlah 50\% variasi dalam pemboleh ubah bersandar (min kerjasama sepasukan). Nilai ini diklasifikasikan tinggi, kerana terdapat banyak faktor yang mempengaruhi prestasi pekerja khususnya kerjasama sepasukan dalam dunia pekerjaan yang semakin bertambah. 
DOI: https://doi.org/10.47405/mjssh.v6i2.631

Jadual 6: Ringkasan model regresi

\begin{tabular}{lccccccc}
\hline Model & $\begin{array}{c}\text { Pemboleh ubah } \\
\text { Dependen }\end{array}$ & $\mathbf{R}$ & $\mathbf{R}^{2}$ & $\begin{array}{c}\mathbf{R}^{2} \\
\text { Terlaras } \\
\left(\text { Adj. } \mathbf{R}^{2}\right)\end{array}$ & $\begin{array}{c}\text { Ralat } \\
\text { Piawai (SE) }\end{array}$ & $\mathbf{F}$ & Sig. \\
\hline $\begin{array}{l}\text { Regresi } \\
\text { Bergand } \\
\text { a }\end{array}$ & $\begin{array}{c}\text { Min prestasi } \\
\text { pekerja }\end{array}$ & $\mathbf{0 . 7 3}$ & $\mathbf{0 . 4 8}$ & $\mathbf{0 . 4 6 3}$ & $\mathbf{0 . 8 5 5 4 2}$ & $\mathbf{2 8 . 2 6 6}$ & $\mathbf{. 0 0 0}$ \\
\hline
\end{tabular}

\section{Ujian signifikan bagi pekali regresi individu}

Nilai pekali piawai beta bagi latihan bercirikan ketenteraan menunjukkan kesinambungan terhadap pengaruh latihan terhadap prestasi pekerja awam. Signifikan pekali beta memberi sokongan terhadap hipotesis alternatif dalam model regresi. Ujian signifikan individu bagi setiap pekali regresi dijalankan menggunakan ujian t. Hipotesis-hipotesis bagi menguji pekali regresi bagi setiap pemboleh ubah regresi seperti berikut:

$$
\begin{aligned}
& H_{0}: \beta_{\imath}=O \\
& H_{1}: \beta_{\imath} \neq O
\end{aligned}
$$

Menguji pekali regresi bukan sahaja memberi pengkaji hasil penemuan mengenai kesesuaian model regresi, malah membantu dalam menilai kekuatan item peramal individu dalam meramal Y. Hasil analisis regresi ini menunjukkan, pekali regresi atau kecerunan bagi latihan bercirikan ketenteraan membentuk tahap kerjasama sepasukan yang tinggi dalam organisasi dan mempunyai pengaruh yang tinggi terhadap min prestasi pekerja awam. Hasil kajian berdasarkan objektif yang pertama menunjukkan, terdapat hubungan yang positif antara latihan bercirikan ketenteraan dalam membentuk kekuatan emosi telah disokong secara empirikal. Seterusnya, hasil kajian berdasarkan objektif yang kedua membuktikan, terdapat hubungan yang positif antara latihan bercirikan ketenteraan dalam membentuk disiplin dan kepimpinan terhadap prestasi pekerja awam telah disokong secara empirikal.

Selain itu, hasil kajian berdasarkan objektif yang ketiga bahawa terdapat hubungan positif antara latihan bercirikan ketenteraan dapat meningkatkan kepatuhan waktu bekerja terhadap prestasi pekerja awam adalah signifikan dan disokong. Hasil kajian ini dapat disimpulkan bahawa, pelaksanaan latihan bercirikan ketenteraan khususnya menggunakan modul ketenteraan yang disesuaikan dengan latar belakang organisasi wajar dilaksanakan secara konsisten dalam sektor kerajaan. Justeru, setiap pekerja haruslah menerima pelaksanaan latihan ini dengan mengubah perspektif bahawa latihan bercirikan ketenteraan ini bukanlah untuk menjadikan seseorang itu sebagai seorang tentera, tetapi dapat menyerapkan ciri-ciri asas tentera yang positif dalam membentuk prestasi pekerja yang terbaik.

\begin{tabular}{|c|c|c|c|c|c|}
\hline \multirow{2}{*}{ Latihan bercirikan ketenteraan } & \multicolumn{2}{|c|}{ Pekali piawai } & \multirow[b]{2}{*}{$\begin{array}{l}\text { Std. } \\
\text { Beta }\end{array}$} & & \\
\hline & $\begin{array}{l}\text { Beta } \\
1.578\end{array}$ & $\begin{array}{l}\text { Ralat } \\
\text { piawai } \\
.344\end{array}$ & & $\begin{array}{c}t \\
4.178\end{array}$ & $\begin{array}{l}\text { Sig. } \\
.000\end{array}$ \\
\hline $\begin{array}{l}\text { Latihan bercirikan ketenteraan membentuk } \\
\text { kekuatan emosi terhadap min prestasi pekerja } \\
\text { awam. }\end{array}$ & .315 & .121 & .336 & 2.574 & $.013 *$ \\
\hline $\begin{array}{l}\text { Latihan bercirikan ketenteraan membentuk } \\
\text { disiplin dan kepimpinan terhadap min prestasi } \\
\text { pekerja awam. }\end{array}$ & .223 & .135 & .146 & .940 & .327 \\
\hline $\begin{array}{l}\text { Latihan bercirikan ketenteraan meningkatkan } \\
\text { kepatuhan waktu bekerja terhadap min } \\
\text { prestasi pekerja awam. }\end{array}$ & 312 & .112 & .354 & 2.772 & $.007 *$ \\
\hline
\end{tabular}

Jadual 7: Perhubungan antara latihan dengan min prestasi pekerja awam 


\section{Kesimpulan}

Tidak dinafikan bahawa latihan di tempat kerja merupakan elemen yang penting dalam membentuk dan mengasah pengetahuan dan kemahiran pekerja. Modul latihan yang bertepatan dengan kehendak organisasi terhadap prestasi pekerja, akan memberi pengaruh kepada tingkah laku pekerja dalam menggalakkan prestasi yang konsisten (Fehrenbacher, 2018). Pekerja merupakan aset dalam sesebuah organisasi kerana tanpa pekerja, segala matlamat, misi dan visi organisasi tidak mampu dicapai (Stirpe et al., 2017). Namun begitu, sekiranya pekerja yang tidak mendapat latihan yang cukup berdasarkan bidang tugas di tempat kerja, maka adalah sia-sia kerana pekerja tersebut tidak mampu untuk melaksanakan tugasan dengan baik kerana tiada pendedahan dan kepakaran tertentu. Bahagian Pengurusan Sumber Manusia dalam organisasi perlu memainkan peranan penting dalam merangka dan melaksanakan program latihan. Hal ini kerana, setiap pekerja wajib mendapatkan latihan secara berkala setiap tahun. Walaupun program latihan yang dijalankan memakan jumlah yang agak besar, tetapi latihan kepada pekerja merupakan pelaburan yang akan memberi impak kepada organisasi (Taylor, 2019).

Artikel ini diharapkan dapat menjadi panduan kepada bahagian pengurusan sumber manusia dan setiap pekerja kerana dapatan kajian dapat menunjukkan kepentingan dan keberkesanan latihan dalam organisasi khususnya latihan yang menerapkan modul ketenteraan. Kertas ini juga barangkali menarik minat pihak pengurusan organisasi kerana mencadangkan prestasi pekerja yang diutamakan, ukuran dan matlamat latihan agar prestasi pekerja memberi anjakan paradigma kepada organisasi. Jika dilihat dari sudut berbeza, kebanyakan pekerja awam menyandang jawatan lain dalam organisasi kemasyarakatan seperti setiausaha jawatankuasa surau perumahan, bendahari organisasi politik dan sebagainya. Oleh kerana prestasi di tempat kerja yang sentiasa mengamalkan prinsip tugas yang efisyen, maka prestasi kendiri dapat menggalakkan budaya kerja organisasi yang lebih terancang serta membentuk kerjasama sepasukan dalam komuniti. Tambahan pula, prestasi diri juga dapat memberi tauladan dan ikutan kepada individu lain dalam mengeratkan semangat kerjasama sepasukan khususnya dalam hidup secara bermasyarakat. Modul latihan ini bukan sahaja memberi manfaat kepada pencapaian matlamat di tempat kerja semata-mata, malah prestasi diri amat bermanfaat untuk disumbangkan kepada komuniti yang memerlukan khidmat dan kepimpinan bersama.

Penemuan kajian ini mencadangkan bahawa organisasi perlu menekankan aspek latihan kepada pekerja yang bersesuaian dengan pembangunan modal insan. Seiring dengan dunia yang semakin maju, setiap organisasi memerlukan pekerja yang benar-benar mempunyai tahap prestasi yang cemerlang (Tisu et al., 2020). Pekerja seharusnya bersaing secara sihat dan saling membantu antara pekerja yang lain dalam menjadikan diri mereka adalah permata dalam organisasi. Pekerja yang bersungguh-sungguh dalam organisasi semestinya akan dinilai dengan markah yang tinggi berdasarkan kemampuan mereka bertugas dan melaksanakan segala perihal dalam organisasi (Van et al., 2018). Penilaian prestasi pekerja akan mempengaruhi status kenaikan pangkat, Indeks Prestasi Utama (KPI) organisasi dan bonus. Menjadi kerisauan semua pekerja sekiranya tidak mempunyai prestasi yang baik dan dinilai dengan markah yang rendah, mereka akan diberhentikan kerja atau dipindahkan ke organisasi yang lain. Latihan yang amat signifikan dilaksanakan di setiap organisasi iaitu modul ketenteraan, segala aspek ketenteraan akan diterapkan dalam diri pekerja tersebut. Bukan untuk menukar status pekerja awam itu sebagai seorang tentera yang bersifat regimental, tetapi mengamalkan nilai dan ciri-ciri seorang tentera. Pekerja awam yang mempunyai tahap pengurusan masa yang cekap, mempunyai mental dan fizikal yang ampuh, berupaya untuk bekerja dalam tekanan tanpa gangguan stres dan mengetahui penjawatan tentera, penyesuaian diri bekerja dengan tentera akan tiada sebarang masalah. Prestasi pekerja awam dan penjawat awam di sektor kerajaan yang cemerlang akan mengubah tanggapan masyarakat bahawa mereka adalah seorang pekerja yang benar-benar berkaliber dan layak untuk bekerja di sektor awam. 


\section{Rujukan}

Fehrenbacher, D. D., Schulz, A. K. D., \& Rotaru, K. (2018). The moderating role of decision mode in subjective performance evaluation. Management Accounting Research, 41, 1-10.

George, D., \& Mallery, P. (2003). SPSS for Windows step by step: A simple guide and reference 11.0 update (4th ed.). Boston: Allyn \& Bacon

Hald, K. S., \& Mouritsen, J. (2018). The evolution of performance measurement systems in a supply chain: A longitudinal case study on the role of interorganisational factors. International Journal of Production Economics, 205, 256-271.

Han, J., Sun, J.-M., \& Wang, H.-L. (2019). Do high performance work systems generate negative effects? How and when? Human Resource Management Review.

He, Y., Donnellan, M. B., \& Mendoza, A. M. (2019). Five-factor personality domains and job performance: A second order meta-analysis. Journal of Research in Personality, 82.

Helton, G. L., Cameron, K. L., Zifchock, R. A., Miller, E., Goss, D. L., Song, J., \& Neary, M. T. (2019). Association Between Running Shoe Characteristics and Lower Extremity Injuries in United States Military Academy Cadets. Am J Sports Med, 47(12), 2853-2862.

Hoch, J. E., \& Dulebohn, J. H. (2017). Team personality composition, emergent leadership and shared leadership in virtual teams: A theoretical framework. Human Resource Management Review, 27(4), 678-693.

Iqbal, M. Z, \& AlSheikh, M. H. (2018). Factors affecting the transfer of training to the workplace after a faculty development programme: What do trainers think? J Taibah Univ Med Sci, 13(6), $552-556$.

Ivarsson, A., Kilhage-Persson, A., Martindale, R., Priestley, D., Huijgen, B., Ardern, C., \& McCall, A. (2019). Psychological factors and future performance of football players: A systematic review with meta-analysis. J Sci Med Sport.

Luria, G., Kahana, A., Goldenberg, J., \& Noam, Y. (2019). Leadership Development: Leadership Emergence to Leadership Effectiveness. Small Group Research, 50(5), 571-592.

Ma, J., \& Peng, Y. (2019). The performance costs of illegitimate tasks: The role of job identity and flexible role orientation. Journal of Vocational Behavior, 110, 144-154.

Mackay, M. M., Allen, J. A., \& Landis, R. S. (2017). Investigating the incremental validity of employee engagement in the prediction of employee effectiveness: A meta-analytic path analysis. Human Resource Management Review, 27(1), 108-120.

O'Neill, T. A., \& Salas, E. (2018). Creating high performance teamwork in organizations. Human Resource Management Review, 28(4), 325-331.

Padlee, S. F., Reimers, V., Mokhlis, S., Anuar, M. M. \& Ahmad, A. (2019). Keep up the good work in research universities: An importance-performance analysis. Australasian Marketing Journal $(A M J)$.

Pagnini, F., Phillips, D., Bercovitz, K., \& Langer, E. (2019). Mindfulness and relaxation training for long duration spaceflight: Evidences from analog environments and military settings. Acta Astronautica, 165, 1-8.

Pfister, J. A., Jack, S. L., \& Darwin, S. N. (2017). Strategizing open innovation: How middle managers work with performance indicators. Scandinavian Journal of Management, 33(3), 139150.

Piirainen, J. M., Rautio, T., Tanskanen-Tervo, M. M., Kyrolainen, H., Huovinen, J., \& Linnamo, V. (2019). Effects of 10weeks of military training on neuromuscular function in non-overreached and overreached conscripts. J Electromyogr Kinesiol, 47, 43-48.

Ronen, S., \& Zuroff, D. C. (2017). How does secure attachment affect job performance and job promotion? The role of social-rank behaviors. Journal of Vocational Behavior, 100, 137-148.

Russell, Z. A., Steffensen, D. S., Ellen, B. P., Zhang, L., Bishoff, J. D., \& Ferris, G. R. (2018). High performance work practice implementation and employee impressions of line manager leadership. Human Resource Management Review, 28(3), 258-270.

Saliba de Oliveira, J. A., Cruz Basso, L. F., Kimura, H., \& Sobreiro, V. A. (2018). Innovation and financial performance of companies doing business in Brazil. International Journal of Innovation Studies, 2(4), 153-164. 
DOI: https://doi.org/10.47405/mjssh.v6i2.631

Saliba de Oliveira, J. A., Cruz Basso, L. F., Kimura, H., \& Sobreiro, V. A. (2018). Innovation and financial performance of companies doing business in Brazil. International Journal of Innovation Studies, 2(4), 153-164.

Stirpe, L., \& Zárraga-Oberty, C. (2017). Are High-Performance Work Systems always a valuable retention tool? The roles of workforce feminization and flexible work arrangements. European Management Journal, 35(1), 128-136.

Taylor, M. A., \& Bisson, J. B. (2019). Changes in cognitive function: Practical and theoretical considerations for training the aging workforce. Human Resource Management Review.

Tisu, L., Lupșa, D., Vîrgă, D., \& Rusu, A. (2020). Personality characteristics, job performance and mental health: the mediating role of work engagement. Personality and Individual Differences, 153.

Van Thielen, T., Bauwens, R., Audenaert, M., Van Waeyenberg, T., \& Decramer, A. (2018). How to foster the well-being of police officers: The role of the employee performance management system. Eval Program Plann, 70, 90-98.

Yuen, K. F., Loh, H. S., Zhou, Q., \& Wong, Y. D. (2018). Determinants of job satisfaction and performance of seafarers. Transportation Research Part A: Policy and Practice, 110, 1-12. 